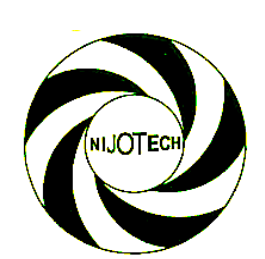

Nigerian Journal of Technology (NIJOTECH)

Vol. 38, No. 2, April 2019, pp. $\mathbf{4 5 6} \mathbf{- 4 6 4}$

Copyright@ Faculty of Engineering, University of Nigeria, Nsukka

Print ISSN: 0331-8443, Electronic ISSN: 2467-8821 www.nijotech.com

http://dx.doi.org/10.4314/njt.v38i2.23

\title{
PROPENSITY TO FLY IN NIGERIA: A FORECAST OF DOMESTIC AIR PASSENGER TRAFFIC FLOW IN SOME NIGERIA AIRPORTS
}

\author{
E. G. Okafor ${ }^{1,}{ }^{*}$, O. C. Buraimoh ${ }^{2}$, K. O. Uhuegho ${ }^{3}$ and M. A. Soladoye ${ }^{4}$ \\ 1, Air Force Institute of TeChnology, NAF Base, Kaduna, Kaduna State, NIGERIA \\ 2,3, Nigerian College of Aviation TeChnology, Zaria Aerodrome, Kaduna, Kaduna State, NIGERIA \\ 4, LinKage Services, KWARA State University, PMB 1530 Malete, KWARA StATE, NIGERIA \\ E-mail addresses: ${ }^{1}$ eg.okafor@gmail.com, ${ }^{2}$ carolinetop456@gmail.com, ${ }^{3}$ kole_k45@yahoo.com \\ 4 musibau.soladoye@kwasu.edu.ng
}

\begin{abstract}
This study carried out an assessment of the air passenger traffic flow in some airports in the six geopolitical zones of Nigeria. Secondary data used in the study was collected from Federal Airport Authority of Nigeria (FAAN) database. Time series features were studied using time series plot and autocorrelation plot against time lag. The forecasting capability of multiplication and additive decomposition models were compared to those of additive and multiplication Holt's Winter methods and the prediction of passenger volume was based on the model with the lowest Mean Square Deviation (MSD) value. The result revealed that Abuja, Kano, Owerri and Yola airports showed upward trend, while Lagos and Port-Harcourt airports showed downward trend. The entire airports with the exception of Yola airport were found to be stationary. The 2017 and 2018 forecast on passenger traffic shows a consistence increase in the total passenger volume for Owerri, Kano and Abuja airports, while Lagos, Yola and Port-Harcourt airports shows slight decrease in the total passenger volume. Based on the results, airport investors should consider investment in Owerri, Kano and Abuja airports, as these airports shows a promising increase in passenger traffic.
\end{abstract}

Keywords: Airport, Decomposition method, Forecast, Holt's winter method, Passenger travel demand, Time series analysis

\section{INTRODUCTION}

In Nigeria, demand for air transport service has been on the increase within the past three decades. Forecasting air passenger demand is of great important for future developmental planning and management purposes [1]. United Kingdom's Department for Transport suggested that $90 \%$ of business travelers wanted the UK government to increase runway and terminal capacities at Heathrow. Following this, runways and terminals have been expanded with the building of Terminal 5. In Nigeria, the same is the case as the Murtala Mohammed Airport (MMA) and Port Harcourt Airport had their runways increased few years back [2].

As future air passenger demand increases, so does the need for investment in aviation infrastructure. Identifying airport investment opportunities with strong growth prospects requires an understanding of trends in the factors affecting revenue growth which is driven primarily by passenger growth and therefore propensity to fly. Thus, there is a need to assess traffic at airport as well as airports operating capacity, which would influence the infrastructure requirement.

According to Taneja [3] the techniques for forecasting air travel can be broadly classified into three categories: judgmental, mechanical and analytical. The choice of any method should be based on several processes including availability of data, accuracy of availability of data, management sophistication and availability of electronic data processing. However, making good predictions is not always easy. It is also an important problem that spans many field including business and industry, government, economics,

* Corresponding author, tel: $+234-816-660-5114$ 
environmental sciences, medicine, social science, politics and finance.

Forecasting problem is often classified as short-term, medium-term and long-term. Short term forecasting problems involve predicting events only a few time periods (days, weeks, months) into the future. Medium-term forecast extend from one to two years into the future and long-term forecasting problems can extend beyond that by many years. Short and medium-term forecasts are required for activities that range from operations management to budgeting and selecting new research and development projects. Long-term forecast impact issues such as strategic planning. Statistical methods are very useful for short term and medium-term forecasting. A common method used in forecasting studies is the time series analysis.

The time series is a chronological sequence of observation on a particular variable. It basically, employs statistical properties of historical data to specify a formal model and then estimate the unknown parameters of it's model using varied techniques such as least square method. This research work implements time series techniques for the forecast of two years air traffic passenger volume.

Schmitz and watts [4] used parametric modelling to forecast wheat yields in the United States, Canada, Australia and Argentina. The essence of this approach was that the data were used for identifying the estimation of the random components in the form of moving average and autoregressive process. They used exponential smoothing to forecast yields in United States and Canada. They also compared the forecasting accuracy between parametric modelling and exponential smoothing.

Kalylen [5] in his study of live hog market using timeseries modeling, analyzed the dynamic relationship between hog market related variables. He developed forecasting models specifically for these variables which were based on Auto Regressive Integrated Moving Average (ARIMA) and Vector Auto Regression (VAR) models. Lineesh and John [6] employed wavelet bases to decompose time series into orthogonal trend series, and then used ARMA and TAR models to forecast each decomposed series, respectively. Krishnamurthy and Yin [7] combined a hidden Markov model and Auto Regression (AR) models under a Markov regime, where AR parameters switch in time according to the realization of a finite-state Markov chain, for nonlinear time series forecasting.
There is lack of available data regarding future passenger volume within Nigeria airports which may affect management as well as stakeholder's decisions on key issues such as infrastructural provision, employment as well as airport investment deals with higher probability of success. It is against this backdrop that this work seeks to forecast future passenger volume for the busiest airport within Nigerian six geopolitical zones. Thus, the objectives of this study are as follows:

i) To determine the time series features for the busiest airport in each of the six geopolitical zone of Nigeria.

ii) To compare and select the superior among two time series modelling technique.

iii) To use the superior of the two modelling techniques from objective (ii) to predict passenger volume in the next two years.

\section{MATERIALS AND METHODS}

\subsection{Study Variables}

Propensity to fly can be explored by analyzing time series data in relation to both the dependent and independent variables. In this study, the passenger volume is the dependent variable while the independent variable is time.

\subsection{Sampling Technique}

Systematic sampling was implemented in this study, which was based on secondary data obtained from FAAN's database. Six airports one from each Nigerian geopolitical zone was used in this study. The selection of an airport from each geopolitical zone was based on annual passenger volume for domestic passengers. Thus, only the busiest airport in each geopolitical zone was considered.

\subsection{Data Collection}

Secondary data was used in this study. The data was collected from Federal Airport Authority of Nigeria (FAAN) database.

\subsection{Data Analysis}

All data analysis in this study were conducted using Minitab software

\subsection{Time Series Features}

\subsubsection{Time series plot}

Time Series plot of the observed data for the six airports considered in this study was developed so as to identify patterns such as trends, seasonality and 
randomness as this patterns play a key role on the model selection.

\subsubsection{Stationarity}

A time series is stationary, if the joint probability distributions of any two observations say $Y_{t}$ and $Y_{t+k}$, is the same for any two time period $t$ and $t+k$ that are separated by the same interval $k$. To determine the stationarity for the time series for finite length considered in this work, auto-covariance and sample autocorrelation function were computed using Equations (1) and (2) respectively $[8,9]$.

$$
\begin{gathered}
c_{k}=Y_{k}=\frac{1}{T} \sum_{t=1}^{T-k}\left(y_{t-\hat{y}}\right)\left(y_{t+k-\hat{y}}\right), k=0,1,2 \ldots K . \\
r_{k}=\rho_{k}=\frac{c_{k}}{c_{o}}, \quad k=0,1,2,3 \ldots K .
\end{gathered}
$$

$K=T / 4$ was used in the study where $T=60$ corresponding to 60 months data collected from Jan 2012 to Dec 2016. For a plot of correlation coefficient $r_{k}$ against time lag $K$, if a sine wave pattern about Zero is observed, the time series can be considered as stationary, otherwise it is non-stationary.

\subsubsection{Forecasting Model Selection}

In this study, two models were considered from which the superior forecasting model that has a lower Mean Square Deviation (MSD) was selected for prediction for each of the airports. The prediction models considered are Holt-Winter's model and Decomposition model.

\subsubsection{Holt's Winters Model}

Winters method [9] was used to provide medium range forecast. It is used when data have both trend and seasonality component, with these two components being either additive or multiplicative. It calculates dynamic estimates for three components: level, trend and seasonality.

The additive model is given in Equations (3) - (6)

$$
\begin{gathered}
L_{t}=\alpha\left(Y_{t}-S_{t-p}\right)+(1-\alpha)\left[L_{t-1}+T_{t-1}\right] \\
T_{t}=\gamma\left[L_{t}-L_{t-1}\right]+(1-\gamma) T_{t-1} \\
S_{t}=\delta\left(Y_{t}-L_{t-1}-T_{t-1}\right)+(1-\delta) S_{t-p} \\
\hat{\mathrm{Y}}_{t}=L_{t-1}+T_{t-1}+S_{t-p}
\end{gathered}
$$

The multiplicative model is given in Equations (7)-(10)

$$
\begin{gathered}
L_{t}=\alpha\left(\frac{Y_{t}}{S_{t-p}}\right)+(1-\alpha)\left[L_{t-1}+T_{t-1}\right] \\
T_{t}=\Upsilon\left[L_{t}-L_{t-1}\right]+(1-\Upsilon) T_{t-1} \\
S_{t}=\delta\left(\frac{Y_{t}}{L_{t-1}+T_{t-1}}\right)+(1-\delta) S_{t-p} \\
\hat{\mathrm{Y}}_{t}=\left(L_{t-1}+T_{t-1}\right) S_{t-p}
\end{gathered}
$$

where,
$L_{t}$ is level component at time $\mathrm{t}, \quad \alpha$ is the weight constant for the level component. $T_{t}$ is the trend component at time $t, r$ is weight constant for the trend component $S_{t}$ is the seasonal component at time $\mathrm{t}, \delta$ is weight constant for the seasonal component. $\mathrm{P}$ is seasonal period and $\mathrm{P}=12$ was used in this study based on the fact that data collected were on a monthly basis. $Y_{t}$ is data value at time $t$ and $\hat{Y}_{t}$ is the fitted value, or one-period-ahead forecast, at time t. $\alpha, \gamma$ and $\delta$ were set as $0.2,0.2,0.2$ respectively in this study.

\subsubsection{Decomposition model}

Decomposition model are used in time series analysis to model time series that shows both the trend and seasonal factors. Decomposition model estimates seasonal effects that can be used to create seasonally adjusted values. A seasonally adjusted value removes the seasonal effect from a value so that trends can be seen more clearly. The two structures considered for basic decomposition models are Additive and Multiplicative given in Equations (11) and (12) respectively.

Additive Model

Multiplication Model

$$
Y_{t}=\text { Trend }+ \text { Seasonal }+ \text { Error }
$$

$$
Y_{t}=\text { Trend } \times \text { Seasonal } \times \text { Error }
$$

where,

$Y_{t}$ is the observation at time $\mathrm{t}$ and the trend component of the decomposition model is estimated using least square regression while the seasonal components are estimated using de-trended series. For an additive decomposition, this is done by subtracting the trend estimates from the series while for a multiplicative decomposition; it is done by dividing the series by the trend values.

\subsubsection{Model Selection}

The model selection of the data was based on Mean Square Deviation (MSD) as given in Equation (13). The model with the lowest Mean Square Deviation (MSD) was selected as a superior prediction model.

$$
\frac{\sum_{t=1}^{n}\left|y_{t}-\hat{y}_{t}\right|^{2}}{n}
$$

$y_{t}$ is actual value at time $\mathrm{t}, \hat{\mathrm{y}}_{t}$ fitted value and $\mathrm{n}$ is number of observation

\subsubsection{Passenger Volume Prediction}

Prediction model which shows lowest (MSD) was selected for the prediction of monthly passenger 
volume for 2017-2018. This was based on the fact that the MSD is a more sensitive measure of an unusually large forecast error. The lower and the upper prediction limits produce a prediction interval for each forecast which is a range of likely values of forecast. Minitab usually repeats the MSD alongside with MAD and MAPE. The Mean Absolute Deviation (MAD) expresses accuracy in the same units as the data which helps conceptualize the amount of error while the Mean Absolute Percent Error (MAPE) expresses accuracy as a percentage of the error.

\section{RESULTS AND DISCUSION \\ 3.1 Sample Selection}

Based on the systematic sample selection approach described in section 2.2, Table 1 shows the total domestic Passenger Volume (PV) for all Nigeria airports in each geopolitical zone for six years and the selected airport for this study analysis.

\subsection{Time Series Analysis}

\subsubsection{Time Series Features}

Table 2 Shows the Time Series features of the observed data for the six airports considered in this study identifying patterns such as trends, seasonality, stationarity together with the non-stationarity of the data as all these are the key determinant of the model used in the forecasting process.

Table 1: Total domestic Passenger Volume (PV) between 2012-2016 and the selected airports

Nigeria Geopolitical Zones Airport/Geopolitical Zones Six years total Passenger Volume (2012-2016) State/Airport Selected

\begin{tabular}{|c|c|c|c|}
\hline \multirow{6}{*}{ South- South } & Edo & 1036914 & \multirow{6}{*}{ Rivers/PortHarcour } \\
\hline & Bayelsa & ----- & \\
\hline & Rivers & 5521707 & \\
\hline & Akwa -lbom & ------ & \\
\hline & Delta & 1131939 & \\
\hline & Cross River & 1016157 & \\
\hline \multirow{6}{*}{ South- West } & Oyo & 338362 & \multirow{6}{*}{ Lagos } \\
\hline & Ekiti & ------ & \\
\hline & Osun & ------- & \\
\hline & Ondo & 38399 & \\
\hline & Lagos & 19905697 & \\
\hline & Ogun & ----- & \\
\hline \multirow{5}{*}{ South-East } & Enugu & 1374900 & \multirow{5}{*}{ Imo/Owerri } \\
\hline & Imo & 1637754 & \\
\hline & Ebonyi & ----- & \\
\hline & Abia & ----- & \\
\hline & Anambra & ----- & \\
\hline \multirow{7}{*}{ North Central } & Niger & 21145 & \multirow{7}{*}{ FCT/Abuja } \\
\hline & Kogi & ----- & \\
\hline & Benue & 3261 & \\
\hline & Plateau & 293456 & \\
\hline & Nasarawa & ----- & \\
\hline & Kwara & 356154 & \\
\hline & FCT & 16126606 & \\
\hline \multirow{5}{*}{ North-East } & Bauchi & ----- & \multirow{5}{*}{ Adamawa/Yola } \\
\hline & Borno & 344272 & \\
\hline & Taraba & ----- & \\
\hline & Adamawa & 679826 & \\
\hline & Gombe & ----- & \\
\hline \multirow{7}{*}{ North West } & Zamfara & $\begin{array}{ll}---- \\
\end{array}$ & \multirow{7}{*}{ Kano } \\
\hline & Sokoto & 414618 & \\
\hline & Kaduna & 746943 & \\
\hline & Kebbi & ---- & \\
\hline & Katsina & 13641 & \\
\hline & Kano & 1228559 & \\
\hline & Jigawa & ----- & \\
\hline
\end{tabular}


Propensity to Fly in Nigeria: A forecast of Domestic Air Passenger Traffic Flow in Some Nigeria Airports, E. G. Okafor, et al.

Table: 2 Time Series Features of the Observed Data

\begin{tabular}{ccccc}
\hline Airports & \multicolumn{4}{c}{ Time Series Features of the Observed data } \\
\cline { 2 - 5 } & Non stationary & Stationary & Trend & Seasonality \\
\hline Abuja & No & Yes & Upward trend & Yes \\
Kano & No & Yes & upward trend & Yes \\
Lagos & No & Yes & downward trend & Yes \\
Owerri & No & Yes & upward trend & Yes \\
PortHarcourt & No & Yes & downward trend & Yes \\
Yola & Yes & No & upward trend. & Yes \\
\hline
\end{tabular}
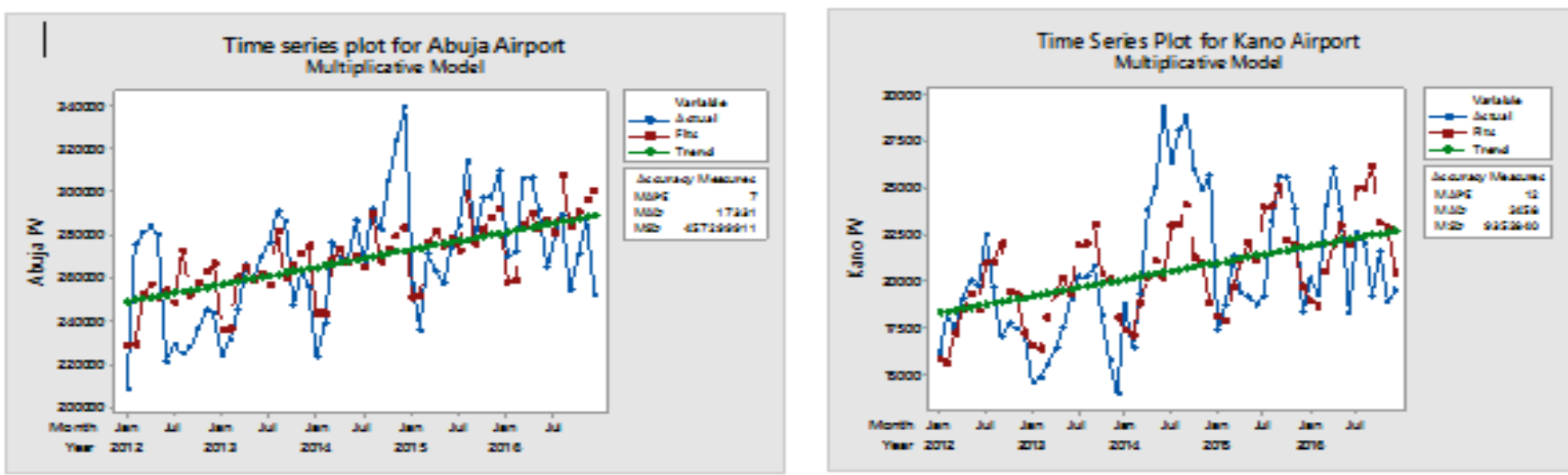

a)

b)
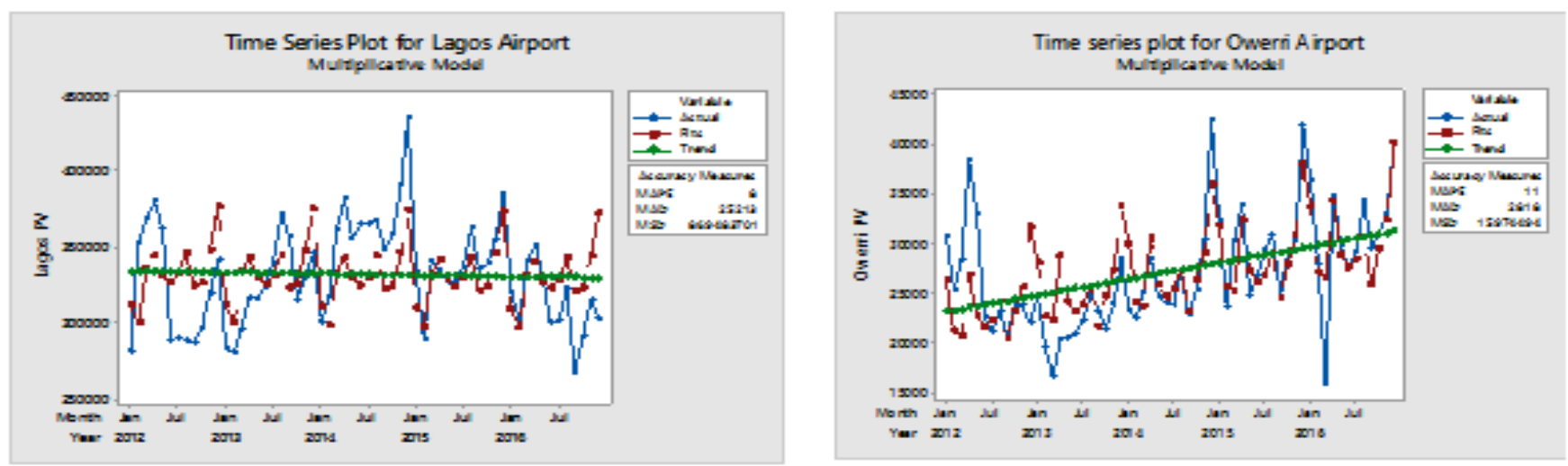

c)

d)
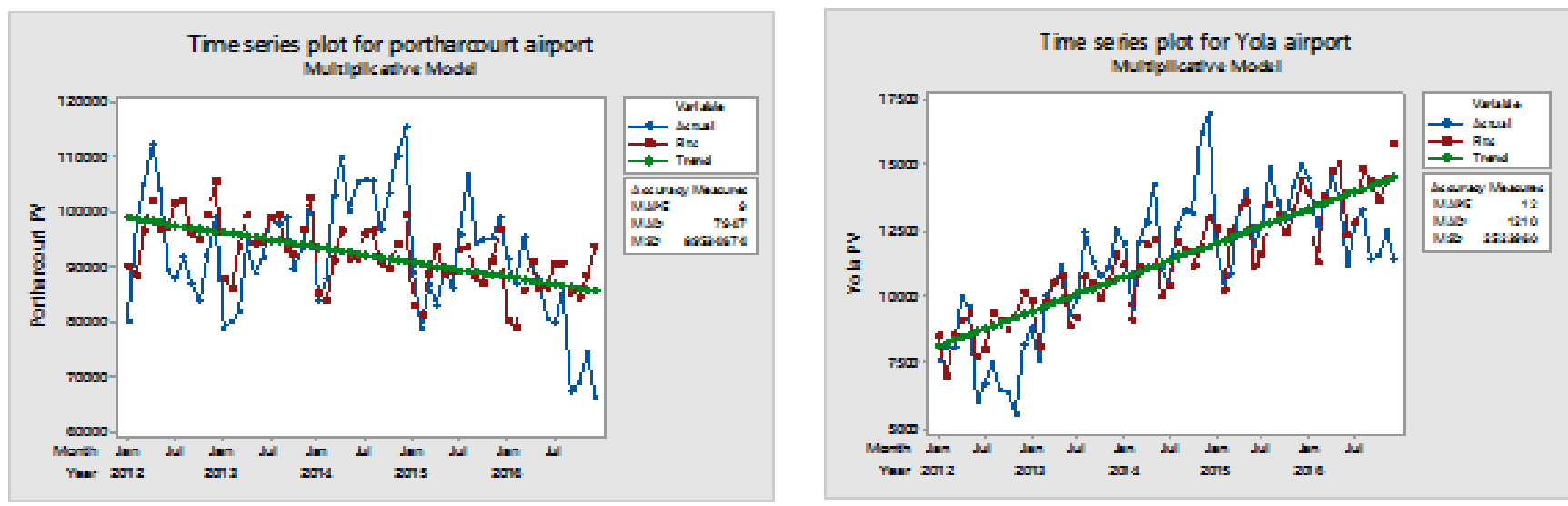

e)

f)

Figure 1: Shows the time series plot with trend and seasonality of the observed data. a) Abuja b)Kano c) Lagos d) Owerri e) PortHarcourt f) Yola. 
All the six airports have both trend and seasonality features. The seasonality of the data is due to the periodic fluctuations in passenger traffic. The stationarity and non-stationarity of all the airports considered was determined from the plot of correlation coefficient $r_{k}$ against time lag $K$ giving a sine wave pattern about Zero which is shown in Figures 1 and 2. Only Yola airport was found to be non-stationary while Abuja, Kano, Lagos, Port Harcourt and Owerri were found to be stationary.
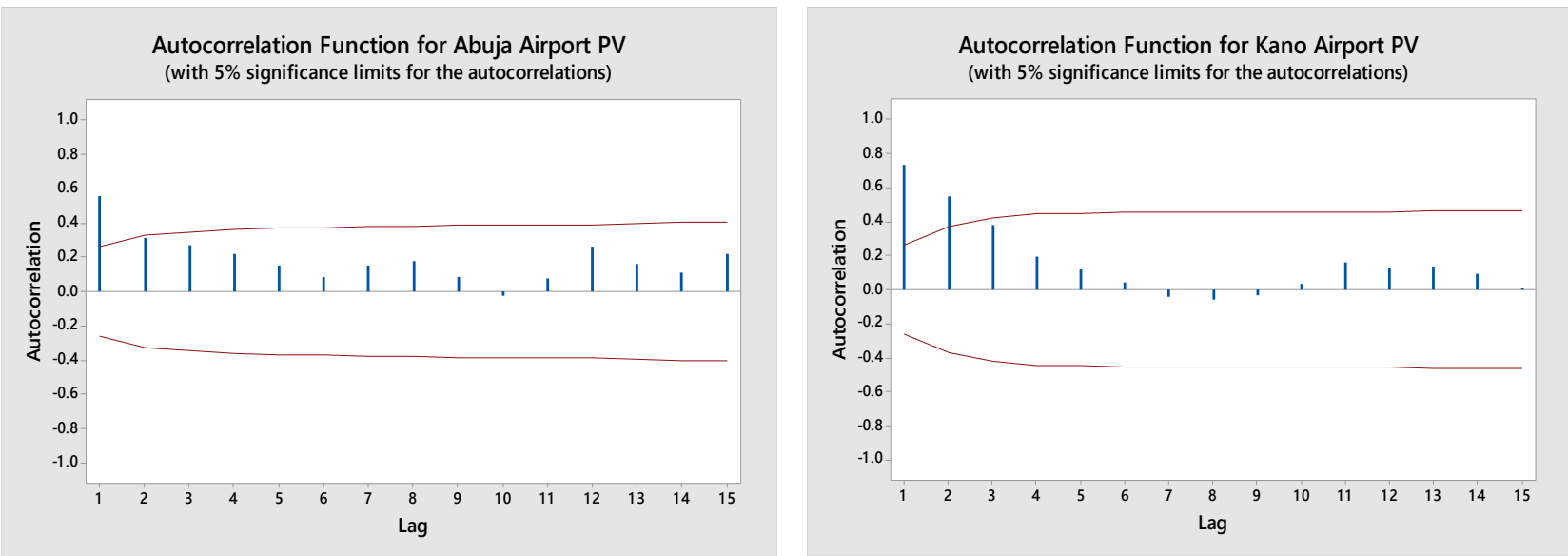

(a)

(b)
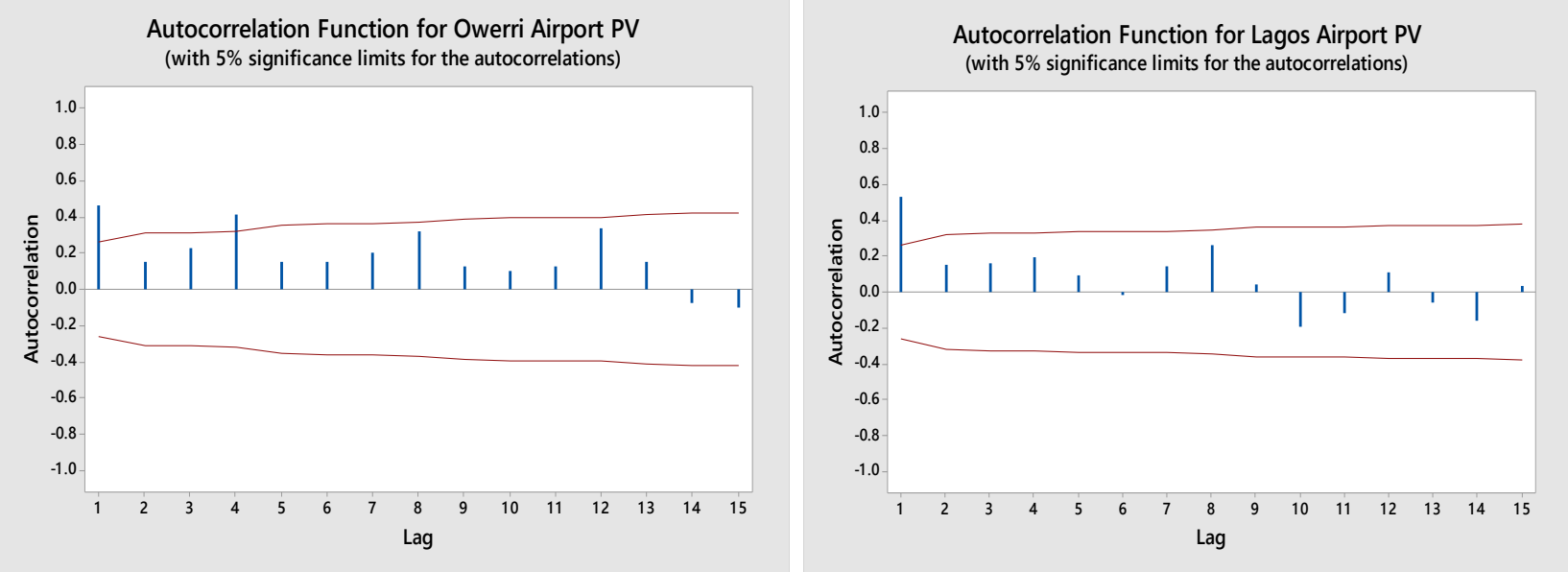

(c)

(d)
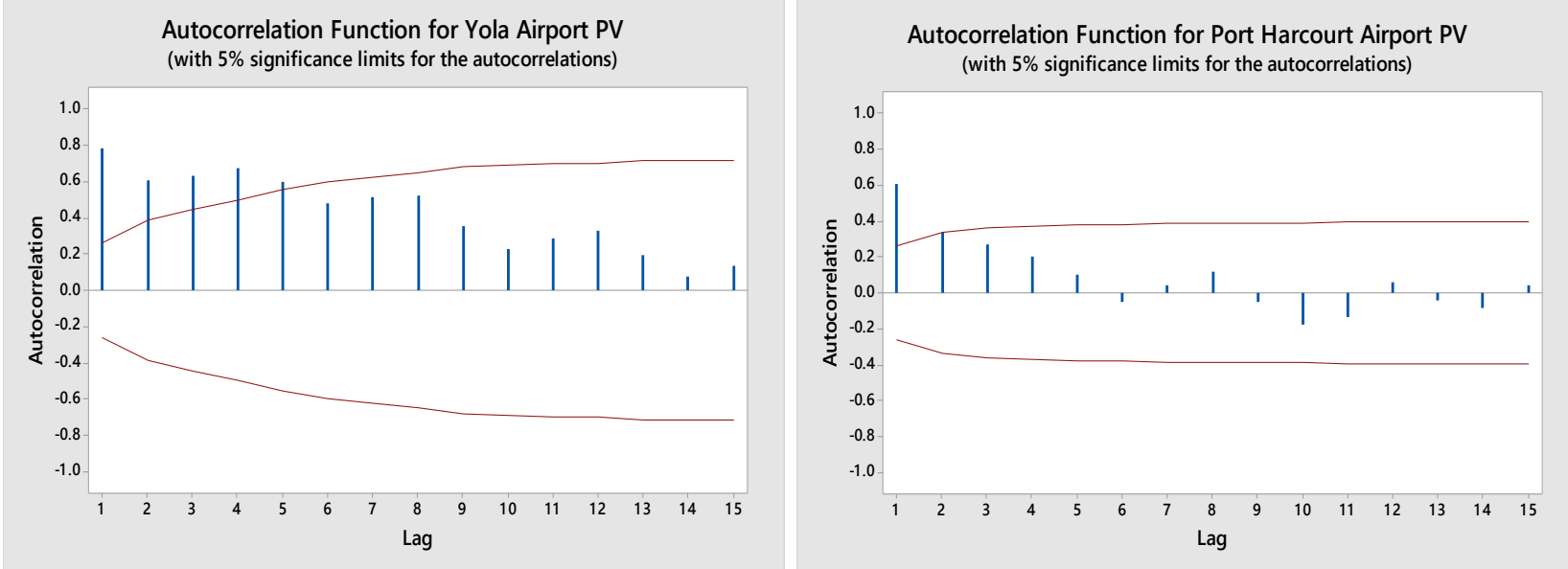

(e)

Figure 2: Shows the autocorrelation plot of the observed data. a) Abuja, b) Kano c) Lagos d) Owerri e) PortHarcourt f) Yola. 


\subsubsection{Model Selection}

The computed result for MSD for Holts-Winter and decomposition models is shown in Table 3 for the six (6) airports considered. Based on the MSD result, Winters multiplicative model was selected for Yola, Port Harcourt, Owerri and Lagos while multiplicative decomposition and additive decomposition model were selected for Abuja and Kano respectively. The selected model were thus used for predictions as shown in Figure 3.

Tables 4 and 5 show the result of the monthly prediction of domestic passenger volume associated with 2017 and 2018 for the six airports considered. In 2017 Abuja has total passenger of 3517379, Kano has 276879 passengers, Lagos has 3037805 passengers, Owerri has 402566, Port-Harcourt has 616714 passengers and Yola has 119993 passengers.

While for 2018, Abuja has total passenger of 3614555, Kano has 287266 passengers, Lagos has 2283568 passengers, Owerri has 437417 passengers, PortHarcourt has 232029 passengers and Yola has 82482 passengers.

Table 3: Comparison and selection of time series modelling technique

\begin{tabular}{|c|c|c|c|c|c|}
\hline \multirow[b]{2}{*}{ AIRPORTS } & \multicolumn{2}{|c|}{ WINTER'S METHOD } & \multicolumn{2}{|c|}{ DECOMPOSITION METHOD } & \multirow[t]{2}{*}{ METHOD SELECTED } \\
\hline & $\begin{array}{l}\text { Additive } \\
\text { Model (MSD) }\end{array}$ & $\begin{array}{l}\text { Multiplicative } \\
\text { Model (MSD) }\end{array}$ & $\begin{array}{l}\text { Additive } \\
\text { Model (MSD) }\end{array}$ & $\begin{array}{l}\text { Multiplicative } \\
\text { Model (MSD) }\end{array}$ & \\
\hline Abuja & 592529020 & 581354163 & 458408875 & 457299911 & $\begin{array}{l}\text { Decomposition } \\
\text { (Multiplication Model) }\end{array}$ \\
\hline Kano & 10993204 & 10501240 & 9344384 & 9352840 & $\begin{array}{l}\text { Decomposition } \\
\text { (Additive Model) }\end{array}$ \\
\hline Lagos & 763486788 & 733684364 & 823345117 & 869483701 & $\begin{array}{l}\text { Winter (Multiplicative } \\
\text { Model) }\end{array}$ \\
\hline Owerri & 15580647 & 13051438 & 16595279 & 15974494 & $\begin{array}{l}\text { Winter (Multiplicative } \\
\text { Model) }\end{array}$ \\
\hline PortHarcourt & 75908873 & 74866152 & 90221340 & 89534674 & $\begin{array}{l}\text { Winter (Multiplicative } \\
\text { Model) }\end{array}$ \\
\hline Yola & 2045839 & 2066284 & 5157547 & 2523960 & $\begin{array}{l}\text { Winter (Multiplicative } \\
\text { Model) }\end{array}$ \\
\hline
\end{tabular}

Table 4: Result of the monthly prediction of passenger volume for 2017(Domestic Passengers)

\begin{tabular}{cccccccccccccc}
\hline AIPORTS & JAN. & FEB. & MAR. & APR. & MAY & JUN. & JUL. & AUG., & SEP. & OCT. & NOV. & DEC. & TOTAL \\
\hline Abuja & 265775 & 266148 & 293001 & 298261 & 290985 & 294735 & 288710 & 316185 & 291839 & 298541 & 304561 & 308638 & 3517379 \\
Kano & 20042 & 19384 & 21568 & 22948 & 23809 & 22583 & 25433 & 25396 & 26748 & 23958 & 23689 & 21321 & 276879 \\
Lagos & 257138 & 252979 & 277684 & 281887 & 266035 & 249117 & 248499 & 256258 & 231538 & 229684 & 240172 & 246814 & 3037805 \\
Owerri & 34969 & 28386 & 27305 & 37694 & 32494 & 30542 & 31788 & 35460 & 30682 & 32995 & 35794 & 44457 & 402566 \\
Port-Harcourt & 60331 & 58391 & 61470 & 60723 & 56503 & 52142 & 51529 & 51328 & 43608 & 41023 & 40725 & 38941 & 616714 \\
Yola & 11459 & 9780 & 10731 & 11681 & 11601 & 8900 & 9214 & 10257 & 9134 & 8685 & 9086 & 9465 & 119993 \\
\hline
\end{tabular}

Table 5: Result of the monthly prediction of passenger volume for 2018 (Domestic Passengers)

\begin{tabular}{cccccccccccccc}
\hline AIPORTS & JAN. & FEB. & MAR. & APR. & MAY & JUN. & JUL. & AUG., & SEP. & OCT. & NOV. & DEC. & TOTAL \\
\hline Abuja & 273213 & 273579 & 301164 & 306551 & 299054 & 302889 & 296679 & 324893 & 299857 & 306725 & 312891 & 317060 & 3614555 \\
Kano & 20908 & 20250 & 22434 & 23813 & 24674 & 23448 & 26298 & 26262 & 27613 & 24823 & 24556 & 22187 & 287266 \\
Lagos & 199931 & 195634 & 213527 & 215480 & 202107 & 188032 & 186294 & 190744 & 171055 & 168350 & 174578 & 177836 & 2283568 \\
Owerri & 38124 & 30928 & 29733 & 41021 & 35341 & 33199 & 34533 & 38500 & 33293 & 35784 & 38798 & 48163 & 437417 \\
Port-Harcourt & 31173 & 28986 & 29159 & 27343 & 23951 & 20587 & 18689 & 16782 & 12514 & 9924 & 7770 & 5151 & 232029 \\
$\quad$ Yola & 8331 & 7048 & 7662 & 8258 & 8117 & 6159 & 6301 & 6926 & 6085 & 5703 & 5874 & 6018 & 82482 \\
\hline
\end{tabular}


(a)

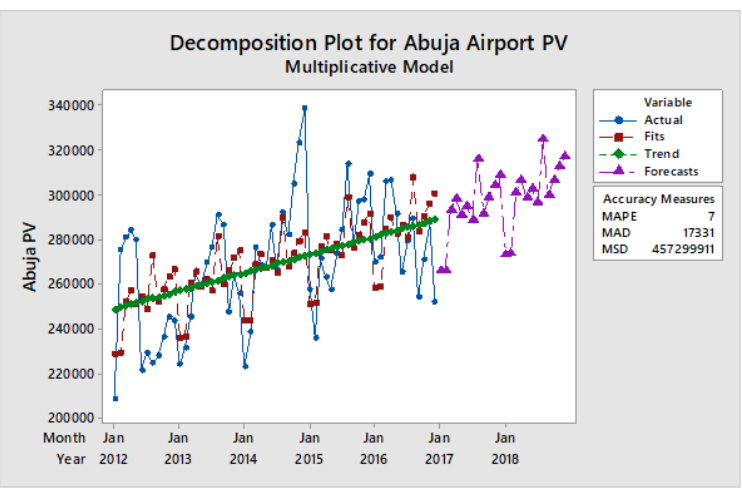

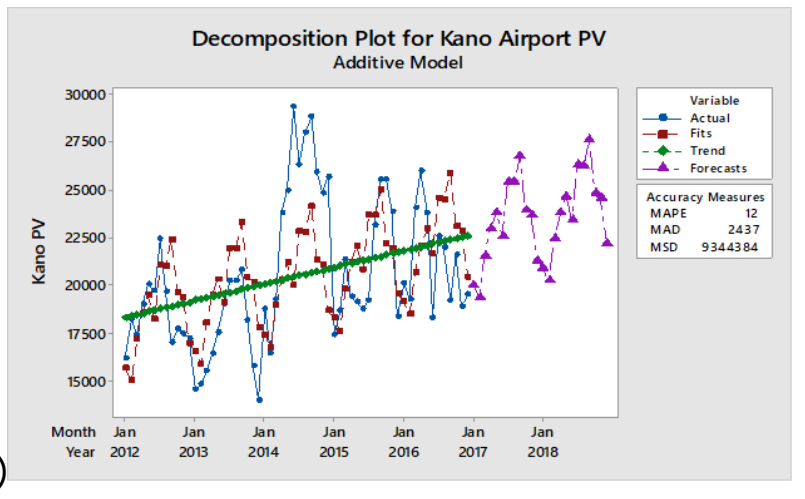

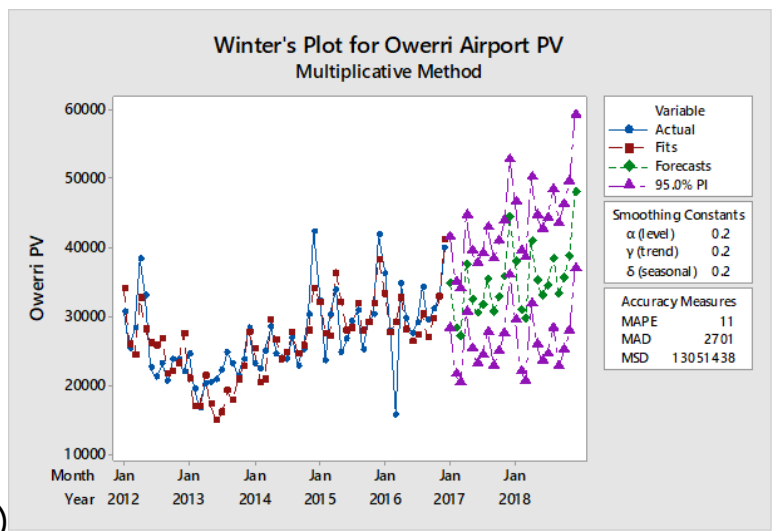

(d)

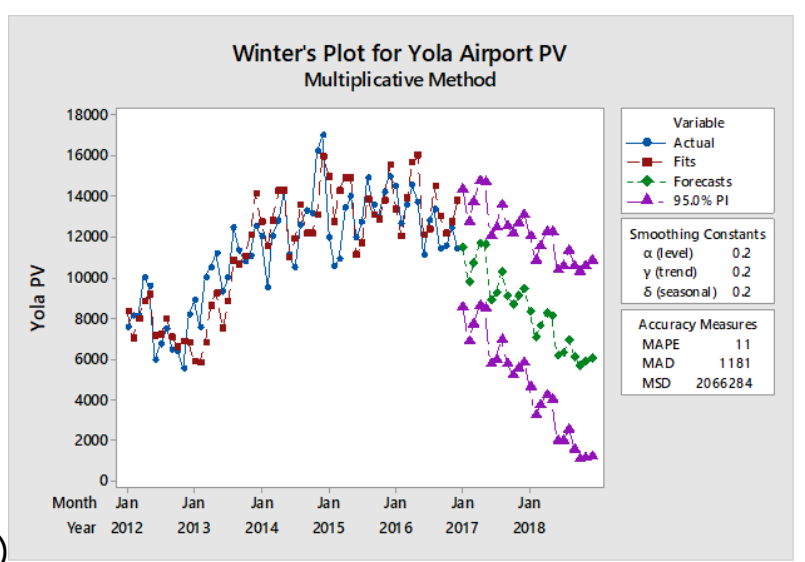

(f)

(e)
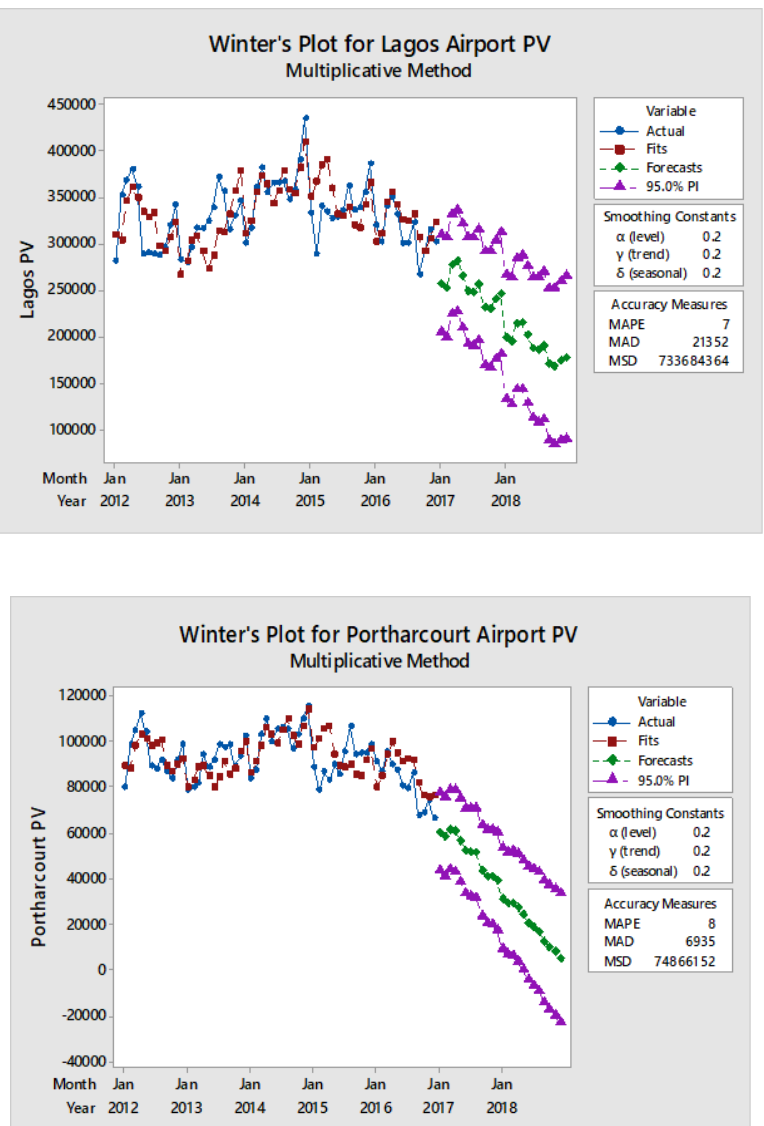

Figure 3: Shows passenger volume predictions for ( $a, b, c, d, e, f)$ corresponding toAbuja, Kano, Lagos, Owerri, Port-Harcourt, Yola airport for 2017 and 2018 respectively.

A comparison of the 2012-2016 historical based total passenger volume data with the 2017 and 2018 predicted value show a consistence increase in the total passenger volume for Owerri, Kano and Abuja airports, while Lagos, Yola and Port-Harcourt airports shows fluctuation in the total passenger volume. Thus, with no doubt Owerri, Kano and Abuja shows promising investment opportunities. However, considering total passenger volume, it is evident that Lagos and Port-Harcourt although showing decrease in total passenger volume, will still guaranty investment protection. Generally, the results indicate non promising investment opportunities for Yola airport.

\section{CONCLUSIONS AND RECOMMENDATION}

In this study, a forecast of air passenger travel demand within Nigerian airports was carried out. Historical data for domestic passenger traffic volume from 2012-2016 were used for the monthly prediction of domestic passenger traffic for 2017 and 2018 for the busiest airport in six geopolitical zones of Nigeria. From the findings of this study, the following conclusions are reached: 
a) Abuja, Kano, Owerri and Yola airports shows an upward trend while Lagos and PortHarcourt airports showed a downward trend with the entire airports having seasonality features. Also the entire airports were found to be stationary except Yola airport.

b) The predicted total passenger volume for 2017 and 2018 were found to be 3517379,276879 , 3037805, 402566, 616714, 119993; and 3614555, 287266, 2283568, 437417, 232029, 82482, for Abuja, Kano, Lagos, Port-Harcourt, Owerri and Yola airports respectively. A comparison of the 2012-2016 historical based total passenger volume data with the 2017 and 2018 predicted value shows a consistence increase in the total passenger volume for Owerri, Kano and Abuja airports, while Lagos, Yola and Port-Harcourt airports shows a slight decrease in the total passenger volume.

c) Owerri, Kano and Abuja airports which show consistence increase in the total passenger volume may have the most promising investment opportunities. However considering total passenger volume, Lagos and Port-Harcourt airport may still be promising in the long run.

Based on the conclusions reached in this work, it is therefore recommended that airport investors should consider investment in Owerri, Kano and Abuja airports, as these airports show a promising increase in passenger traffic.

\section{REFERENCES}

[1] A. S. Fernando and M. Priyadarshana, "Modeling air passenger demand in Bandaranaike International Airport, Sri Lanka,"
Journal of Business \& Economic Policy, vol. 2, no. 4, pp. 146 - 151, December 2015.

[2] M. Stephens, "Port Capacity and Utilization," Unpublished M.Sc. Dissertation, 2013.

[3] N. K. Taneja, "A model for forecasting future air travel demand on the North Atlantic," Flight Transportation Laboratory, Massachusetts Institute of Technology USA, 1971.

[4] A. Schmitz and D. Watts, "Time series modeling for forecasting wheat production of Paskistan Theory Tests and Empirical Results," Transportation Research, vol. 17B, no. 3, pp. $175-191,1970$.

[5] M.S. Kaylen, "Vector autoregression forecasting model suggested improvements" Annual Meeting of American Agricultural Economics Association, July 27-30,1986.

[6] M. Lineesh and C. John, "Analysis of nonstationary time series using waveletdecomposition," Nature and Science, vol. 8, no. 1, pp. 53 - 59, 2010.

[7] V. Krishnamurthy and G. Yin, "Recursive algorithms for estimation of hidden Markov models and autoregressive models with Markov regime," IEEE Transactions on Information Theory, vol. 48, no. 2, pp. 458 - 476, 2002.

[8] O. R. Nwaogbe, H. Wokili, V. Omoke and B. Asiegbu, "An analysis of the impact of air transport sector to economic development in Nigeria," Journal of Business and Management, vol. 14, no. 5, pp. 41 - 48, 2013.

[9] D.C. Montgomery, C.L. Jenning and M Kulahci, "Introduction to time series analysis and forecasting" John Wiley \& Son, Inc, Publication, 2008. 